\title{
Purification of Two Different Immunoglobulins (Igs) from Olive Flounder Paralichthys olivaceus and Analysis of Lactococcus garvieae Antigens by the Igs
}

\author{
Gee Wook Shin ${ }^{1}$, Young Rim Kim¹, Yong Seung Shin ${ }^{1}$, Eung Goo Lee ${ }^{1}$, \\ Myung Joo $\mathrm{Oh}^{2}$, Terutoyo Yoshida ${ }^{3}$ and Tae Sung Jung ${ }^{1 *}$ \\ ${ }^{1}$ Laboratory of Fish \& Shellfish Diseases, College of Veterinary Medicine, \\ Gyeongsang National University, Chinju 660-701, Korea \\ ${ }^{2}$ Department of Fish Pathology, Yosu National University, \\ Yosu 550-747, Korea \\ ${ }^{3}$ Department of Biological Production and Environmental Science, \\ Faculty of Agriculture, Miyazaki University, \\ Miyazaki 889-2192, Japan
}

(Received February 24, 2006)

\begin{abstract}
Immunoglobulins (Igs) were purified from sera obtained from olive flounder Paralichthys olivaceus immunized with goat IgG using immunoaffinity and mannan-binding protein (MBP) affinity columns and designated IMMIg and MBPIg respectively. SDS-PAGE and two-dimensional gel electrophoresis (2-DE) analyses demonstrated that the olive flounder serum contained at least two different types of Ig in terms of molecular weight and pl of heavy chain. 2-DE separation of the Igs followed by peptide mass fingerprinting using matrix-assisted laser desorption/ionization time of flight mass spectrometry (MALDI-TOF MS) revealed that these two lgs were IgM and IgM precursor of olive flounder. Monoclonal antibodies (MAbs) were raised against the IMMIg and MBPIg and proteome analysis of Lactococcus garvieae using these MAbs and olive flounder immune sera demonstrated that IMMIg and MBPIg recognized different antigens of L. garvieae. This suggested that different Igs are possibly involved in protecting olive flounder against $L$. garvieae infection.
\end{abstract}

Keywords: Paralichthys olivaceus, Lactococcus garvieae, immunoglobulin, affinity chromatography, immunoproteomics, monoclonal antibodies, olive flounder

The olive flounder Paralichthys olivaceus is an important mariculture fish species in Korea, China and Japan. In Korea, this species is mainly cultured in landbased tanks, and its production reached 32,141 metric tons in 2004 (2005 Statistics, Ministry of Maritime Affairs \& Fisheries, Korea Government). However, the intensive culture of this species has led to the emergence of various parasitic, bacterial and viral diseases, which have triggered severe economic losses. A more thorough understanding of fish defense mechanisms against various infectious diseases is highly needed for the development of appropriate health management strategies and sustainable aquaculture production.

The defense mechanisms of vertebrates are gener-

\footnotetext{
* Corresponding author

E-mail: jungts@gsnu.ac.kr
}

ally divided into the innate and acquired immune responses. Acquired immune responses involve the production of specific immunoglobulins (Igs) by the host following antigen stimulation. The produced Igs protect the host by removing the pathogen or preventing it from spreading into the blood or organs. Mammals possess five classes of $\lg M$, IgG, IgA, IgE and IgD (Tizard, 2000). On the other hand, fishes have been reported to have 3 isotypes of the $\mathrm{lg}$ in genomic study, namely $\mathrm{lgM}$ (Lee et al., 2001; Hordvik et al., 2002), IgD (Hirono et al., 2003), IgZ/lgT (Danilova et al., 2005; Hansen et al., 2005). Of these Igs, tetramer IgM has been reported to play an important role in humoral immune response of fish (Kaattari and Piganelli, 1996; Tizard, 2000). On the other hand, two forms of IgMs, high molecular protein (HMW) and low molecular protein (LMW) IgM, have been reported from some fish species, such as olive 
flounder (Bang et al., 1996), giant grouper Epinephelus itaira (Clem, 1971), rainbow trout (Elcombe et al., 1985), channel catfish Ictalurus punctatus (Lobb and Olson, 1988) and carp Cyprinus carpio (Rombout et al., 1993). In ollive flounder, LMW IgM purified from hyperimmune sera against Edwardsiella tarda showed different agglutination titer from that of the HMW IgM (Bang et al., 1996).

A large variety of techniques have been used to purify Igs from fish serum, including precipitation in saturated ammonium sulfate, gel filtration, ion exchange chromatography and affinity chromatography. Affinity columns bound with specific ligands, such as protein $A$, mannan binding protein (MBP) and specific protein, have been widely used for purifying IgM from fish sera due to their methodological simplicity and specificity to $\operatorname{lgM}$ (Suzuki et al., 1990; Al-Harbi et al., 2000; Watts et al., 2001; Crosbie and Nowak, 2002; Bromage et al., 2004).

Immunoproteomic tools to study immune response, such as two-dimensional gel electrophoresis (2-DE), immunoblotting and peptide mass fingerprinting (PMF) using matrix-assisted laser desorption/ionization time of flight mass spectrometry (MALDI-TOF MS), have been widely used for separation of crude proteins/antigens and their identification from cells, tissues, body fluids, or organism lysates (Görg et al., 2000; Mini et al., 2006; Twine et al., 2006). In these ways, proteomic tools have been proven highly useful for studying pathogenesis, exploring markers for diagnosis and vaccines development.

Lactococcus garvieae has been identified as a causative agent of fish streptococcosis (Roberts, 2001) in many species worldwide, including olive flounder (Shin et al., 2006a), rainbow trout Oncorhynchus mykiss (Chang et al., 2002), and yellowtail Seriola quinqueradiata (Kusuda et al., 1976). In spite of importance as a fish pathogen, there were few studies about antigens of this bacterium recognized by host fish (Kang et al., 2006; Ooyama et al., 2002). Recently, we constructed partial 2-DE reference map for L. garvieae (Shin et al., 2006b) which might be highly useful in identifying antigenic proteins on 2-DE immunoblotting profile. In the present study, we produced monoclonal antibodies (MAbs) for two different IgMs purified from olive flounder. Using these MAbs and olive flounder immune serum, immunoproteomic analysis of $L$. garvieae was carried out to understand humoral immune response of olive flounder against $L$. garvieae infection.

\section{Materials and Methods}

Fish and preparation of immune sera

Olive flounders (body weight $300-400 \mathrm{~g}$ ) were purchased from a commercial fish farm and maintained in fiber reinforced plastics (FRP) tanks provided with recir- culated seawater maintained at $18-20^{\circ} \mathrm{C}$. Fifteen fish were immunized by intraperitoneal injection with goat $\lg G(250 \mu \mathrm{g} / 100 \mathrm{~g}$ body weight) mixed 1:1 (v/v) with Freund's complete adjuvant. Identical second and third booster doses were administered at two-week intervals. One week after the third injection, the fish were bled from their caudal veins, and the collected sera were kept at $-70^{\circ} \mathrm{C}$ until use. Ten fish injected with phosphate buffered saline (PBS; $140 \mathrm{mM} \mathrm{NaCl}, 2.7 \mathrm{mM}$ $\mathrm{KCl}, 1.5 \mathrm{mM} \mathrm{KH}_{2} \mathrm{PO}_{4}$, and $8.1 \mathrm{mM} \mathrm{Na} 2 \mathrm{HPO}_{4}, \mathrm{pH} 7.2$ ) were used as controls and harvested for non-immunized sera.

\section{Purification of fish antibodies}

Protein A, mannan binding protein (MBP) and immunoaffinity columns were used to purify Igs from immunized sera.

(a) Protein A affinity columns

Protein A beads (Sigma, USA) were used to purify Igs from immunized olive flounders, according to Bollag et al. (1996) with slight modification. Briefly, $1 \mathrm{mg}$ of protein $\mathrm{A}$ beads were packed in disposable polystyrene columns $(0.8 \times 4 \mathrm{~cm}$, Bio-Rad, USA) and washed with binding buffer ( $10 \mathrm{mM}$ Tris, $1.25 \mathrm{M} \mathrm{NaCl}, 20 \mathrm{mM} \mathrm{CaCl}$, $0.02 \% \mathrm{NaN}_{3}, \mathrm{pH} 7.4$ ). Serum samples were mixed with binding buffer (1:1) and applied to the columns. Unbound materials were removed with $150 \mathrm{~mL}$ of binding buffer, and the Igs were eluted using elution buffer (10 mM Tris, $1.25 \mathrm{M} \mathrm{NaCl}, 0.02 \% \mathrm{NaN}_{3}, \mathrm{pH}$ 7.4) with 1 $\mathrm{mL}$ fractions collected in microtubes containing $0.1 \mathrm{~mL}$ of $0.1 \mathrm{M}$ Tris buffer, $\mathrm{pH} 7.4$.

(b) Mannan binding protein (MBP) affinity columns

Igs were purified from immunized olive flounder using the ImmunoPure ${ }^{\circledR} \operatorname{IgM}$ Purification Kit (Pierce, USA). Briefly, the $5 \mathrm{~mL}$ columns prepacked were prewashed with $5 \mathrm{~mL}$ of preparation buffer and then equilibrated with $20 \mathrm{~mL}$ of binding buffer. Serum samples were mixed with binding buffer (1:1) and applied to the columns, which were then incubated for $30 \mathrm{~min}$ at $4^{\circ} \mathrm{C}$. After unbound materials were removed with 42 $\mathrm{mL}$ of binding buffer, columns were loaded with $3 \mathrm{~mL}$ elution buffer and incubated for $1 \mathrm{~h}$ at room temperature (R.T.), and the elutes were fractionated as above.

(c) Immunoaffinity columns

Igs were immunoaffinity purified from immunized olive flounder sera according to the method of Smith (1992). Briefly, columns $(0.8 \times 4 \mathrm{~cm}$, Bio-Rad, USA $)$ containing $2 \mathrm{mg}$ of goat IgG agarose beads (Sigma, USA) were washed with $150 \mathrm{~mL}$ PBS and loaded with serum samples mixed 1:1 with PBS. After the columns were washed with $150 \mathrm{~mL}$ PBS, the Igs were eluted with elution buffer $(0.1 \mathrm{M}$ glycine- $\mathrm{NaOH}, \mathrm{pH} 11)$, and $1 \mathrm{~mL}$ fractions were collected in microtubes containing $0.1 \mathrm{~mL}$ of $0.1 \mathrm{M}$ Tris buffer, $\mathrm{pH}$ 7.4. The elutes containing Igs were desalted and concentrated by centrifugation with PBS in Centricon (Falcon, USA). The concentrations of 
purified proteins were measured using the Bradford reagent (Bio-Rad, USA) with spectrophotometer at 595 $\mathrm{nm}$.

SDS-PAGE and two-dimensional gel electrophoresis (2$D E)$ of purified lgs

SDS-PAGE was performed under reducing to elucidate the molecular weights of the purified Igs. For reducing conditions, purified Igs $(0.3 \mu \mathrm{g})$ were mixed with SDS-PAGE sample buffer ( $60 \mathrm{mM}$ Tris- $\mathrm{HCl}, 25 \%$ glycerol, 2\% SDS, $14.4 \mathrm{mM}$ 2-mercaptoethanol, 0.1\% bromophenol blue) and boiled for $10 \mathrm{~min}$ at $100^{\circ} \mathrm{C}$. The denatured proteins were resolved on $12.5 \%$ gels at $50 \mathrm{~V}$ for $15 \mathrm{~min}$ and then at $100 \mathrm{~V}$ until the dye reached the bottom of the gel. 2-DE was performed as described by Görg et al. (2000), with slight modification. Affinity column purified lgs were diluted to $1 \mathrm{mg} / \mathrm{mL}$ with rehydration buffer (9 M urea, 4\% CHAPS, $20 \mathrm{mM}$ DTT, 0.5\% IPG buffer, pH 4-7, and trace amounts of bromophenol blue), then microcentrifuged at $16,000 \times g$ for $10 \mathrm{~min}$ (R.T.). The supernatants were subjected to isoelectricfocusing with immobilized $\mathrm{pH}$ gradient (IPG) strips (Immobiline DryStrip, pH 4-7, 0.5 ×3×70 mm; Amersham Biotech, Sweden) using the IPGphor system (Amersham). The automated run consisted of $6 \mathrm{~h}$ at 30 $\mathrm{V}, 6 \mathrm{~h}$ at $60 \mathrm{~V}$, and a gradual voltage increase to $4,500 \mathrm{~V}$ for a total $56 \mathrm{kVh}$. The focused IPG strips were placed on $12.5 \%$ SDS-PAGE gels, sealed with $0.5 \%(\mathrm{w} / \mathrm{v})$ agarose and electrophoresed until the dye reached the bottom of the gel. The bands on SDS-PAGE and spots on 2-DE gels were visualized with CBB G-250, digitized with an Agfa Arcus $1200^{\text {TM }}$ image scanner (Agfa-Gevaert, Mortsel, Belgium) and analyzed using the Phoretix ${ }^{\mathrm{TM}}$ 2D software (Ver. 5.01, NonLinear Dynamics Ltd., UK). Identification of Igs was conducted by peptide mass fingerprinting (PMF) using MALDI-TOF MS followed by SDS-PAGE and 2-DE analysis, as described by Shin et al. (2006b).

\section{Production of monoclonal antibodies (MAbs)}

BALB/c mice (Hyochang Science Inc., Korea) were immunized with Igs purified immunoaffinity and MBP affinity column from immunized sera, according to the method described by Al-Harbi et al. (2000). Briefly, 50 $\mu \mathrm{g}$ of olive flounder Igs mixed 1:1 with Freund's complete (first) or incomplete (second and third) adjuvants were injected intraperitoneally every 2 weeks for 6 weeks. After 1 week of the third injection, mice were boosted with $50 \mu \mathrm{g}$ of Igs without adjuvant through tail vein injection. Three days after the adjuvant-free booster shot, spleen cells were harvested from immunized mice and fused with Sp2/o myeloma cells (CRL-1581, ATCC, USA) using polyethylene glycol. The fused cells were cultivated on a feeder layer of mouse blood cells in 96well plates. MAbs were screened by ELISA and immunoblotting assay.
2-DE immunoblotting for L. garvieae KG9408 with MAbs

MAbs were used in 2-DE immunoblot assays to determine whether the two different IgMs reacted with $L$. garvieae antigens. Briefly, 2-DE and its immunoblotting assays for $L$. garvieae was performed as described by Shin et al. (2006b) and Kang et al. (2006), respectively. 2-DE gels were stained with silver nitrate for visualization of the protein spots, or transferred to a PVDF membrane (0.45 $\mu \mathrm{m}$; Millipore, USA). The membranes were blocked with $5 \%$ skim milk in PBS-T for $1 \mathrm{~h}$ (R.T.), washed three times with PBS-T, and then incubated for $4 \mathrm{~h}$ (R.T.) with antisera (1:20) collected from olive flounder on 6th week of post-infection with $L$. garvieae KG9408 (10 $\mathrm{CFU/fish,} \mathrm{intraperitoneal} \mathrm{injection).} \mathrm{The}$ membranes were washed 3 times with PBS-T and separately incubated with M11A1-4 and G7G4-6 clones for each $\lg$ for $4 \mathrm{~h}$ (R.T.) L. garvieae antigenic spots were visualized by incubation with goat HRP-conjugated antimouse IgG (Jackson, USA; 1:4,000) for $1 \mathrm{~h}$ at R.T.. The both membranes were then washed four times with PBS-T for 15 min, developed using an Enhanced Chemiluminescent $(E C L)$ kit (Amersham Biosciences) and exposed to $x$-ray film for visualization of the antigenic proteins. The stained gels and immunoblotted membranes were digitized with an Agfa Arcus $1200^{\mathrm{TM}}$ image scanner (Agfa-Gevaert, Belgium) and the acquired images were analyzed using the Phoretix 2D software (Ver. 5.01; NonLinear Dynamics, UK). Antigenic spots were identified by comparison to a partial 2-DE reference map of L. garvieae KG9408 previously constructed in our laboratory (Shin et al., 2006b) and the 2-DE immunoblot maps generated during the present study.

\section{Results}

\section{Affinity column purification of olive flounder lgs}

The MBP affinity and immunoaffinity columns were able to successfully purify Igs from serum samples taken from goat lgG-immunized olive flounders. The concentrations of purified Igs were as follows: immunoaffinity columns, $1.2 \pm 0.2 \mathrm{mg} / \mathrm{mL}$; MBP affinity columns, $0.9 \pm$ $0.2 \mathrm{mg} / \mathrm{mL}$. Goat IgG- and MBP-positive Igs were named as IMMIg and MBPIg, respectively. In contrast, the protein A affinity column was not able to purify any protein from immunized or non-immunized olive flounders.

\section{SDS-PAGE and 2-DE of purified lgs}

Igs purified using the two different columns were subjected to SDS-PAGE and 2-DE analysis (Fig. 1 and 2). In SDS-PAGE analysis, IMMIg yielded three bands of 66,27 and $25 \mathrm{kDa}$ and MBPIg showed three bands of approximately 68, 27 and $25 \mathrm{kDa}$ (Fig. 1). In 2-DE analysis, the spot distribution in the 2-DE profile of IMMIg could be divided into two groups: (a) those in the range of pl 5.08-6.41 and MW $66 \mathrm{kDa}$, believed to be 


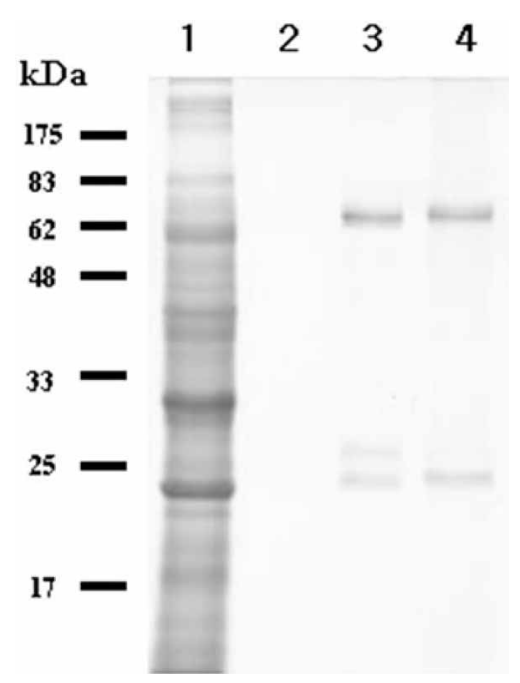

Fig. 1. SDS-PAGE analysis of olive flounder Igs purified from immunized sera using protein $A$, immunoaffinity and MBP columns. Lane 1, whole sera of olive flounder; lane 2, Ig purified with protein A affinity column; lane 3, Ig purified with immunoaffinity column; lane 4 , Ig purified with MBP affinity column.

the heavy chain; and (b) those broadly distributed across the range of $p \mathrm{l} 4-7$ and $\mathrm{MW} 25-28 \mathrm{kDa}$, representing the light chain (Fig. 2 A). In the case of MBPIg (Fig. 2 B), 2$\mathrm{DE}$ profile showed five groups: (c) those in the range of pl 5.30-5.73 and MW $68 \mathrm{kDa},\left(\mathrm{a}^{\prime}\right)$ those in the range of pl 5.35-6.30 and MW $66 \mathrm{kDa}$, (d) those in the range of pl 5.03-5.32 and M.W 47-49 kDa, (e) those in the range of $p l$ 4.59-4.92 and MW 47-45 kDa and ( $\left.b^{\prime}\right)$ those in the range of and $p l$ 4-7 and MW 25-28 kDa. In these groups, group ( $\left(a^{\prime}\right)$ and $\left(b^{\prime}\right)$ were found to correspond with group (a) and (b) on 2-DE profile of IMMlg in computational image analysis.

\section{Identification of Igs}

After image analysis of the SDS-PAGE and 2-DE separations of IMMIg and MBPIg, the respective bands and spots were identified by PMF followed by MALDITOF MS (data not shown). The SDS-PAGE bands seen at 66 and $68 \mathrm{kDa}$ were identified as the immunoglobulin M (Accession No. 14475599) or IgM precursors (Accession No. 7025429) of the olive flounder. These proteins were also identified from all spots of groups (a), (c), ( $\left.a^{\prime}\right)$ and (d) in the 2-DE profiles of IMMIg and MBPIg. On the other hand, the bands of 25 and $27 \mathrm{kDa}$ of SDS-PAGE and groups of (b), (b') and (e) on 2-DE profiles could not be identified from the olive flounder protein database.

\section{Production of MAbs for IMMIg and MBPIg}

Antibodies against IMMIg and MBPIg were generated in mice. ELISA screening followed by SDS-PAGE immunoblot assays allowed selection of $30 \mathrm{MAb}$ clones for IMMIg and 25 MAb clones for MBPIg. Of the MAbs for IMMlg, 24 clones including G7G4-6 were specific for the heavy chain and 1 clone (G11B10-1) was specific for the $27 \mathrm{kDa}$ light chain (Fig. 3A). Of the MAbs for MBPIg, 29 clones including M11A1-4 were specific for the heavy chain and 1 clone (M7C3-4) was specific for the $27 \mathrm{kDa}$ light chain (Fig. 3B). Immunoblot assays of IMMIg and MBPIg revealed that the MAbs strongly recognized their homologous antigens, but reacted only weakly with the heterologous antigen (Fig. 3C). Of the tested MAbs, M11A1-4 and G7G4-6 were selected and used to compare antigenic spots reacting with MBPIg and IMMIg in 2-DE immunoblot assays of L. garvieae.

\section{Comparisons of 2-DE immunoblot profiles of L. garvieae KG9408 \\ 2-DE immunoblot assays using the generated MAbs} were used to compare L. garvieae antigen recognition by the two different types of $\mathrm{IgM}$ purified from olive flounder. The detected antigenic spots were identified by comparison to a partial $2-D E$ reference map of $L$.

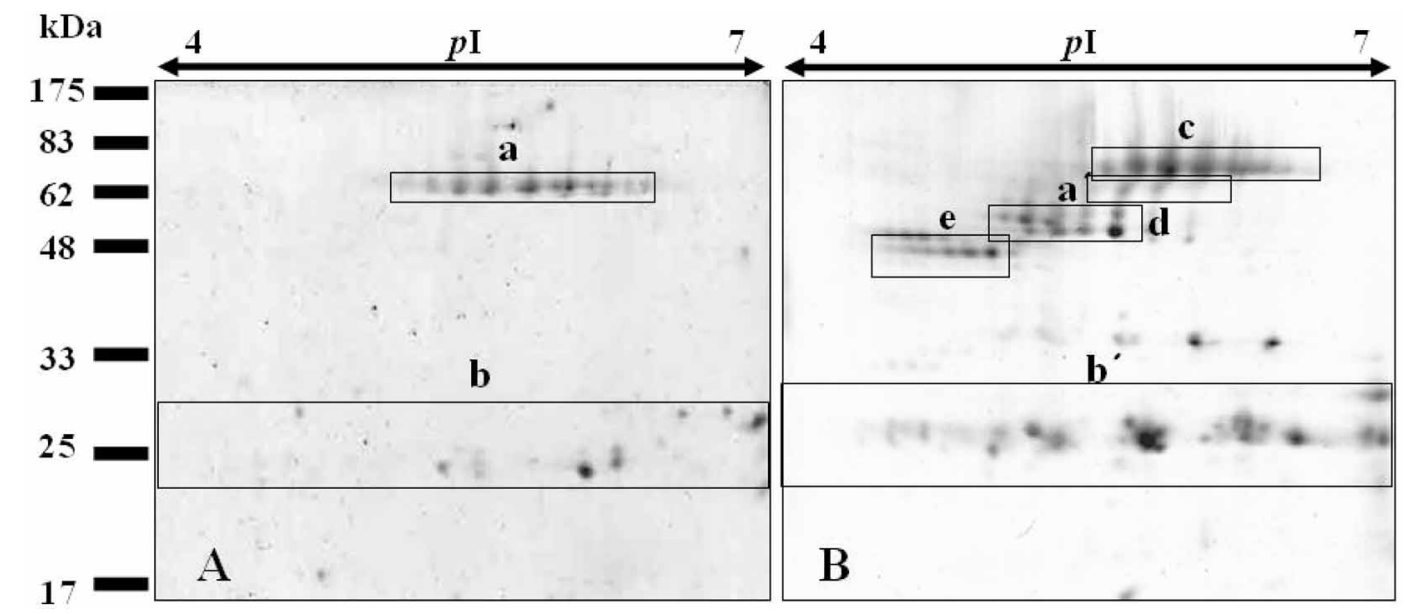

Fig. 2. 2-DE analysis of the purified immunoaffinity-positive Ig (IMMlg; A) and MBP-positive Ig (MBPIg; B). 2-DE was performed using pH 4-7 IPG strips $(7 \mathrm{~cm}$ ) for the first dimension (IEF) and $12.5 \%$ SDS-PAGE for the second dimension. 


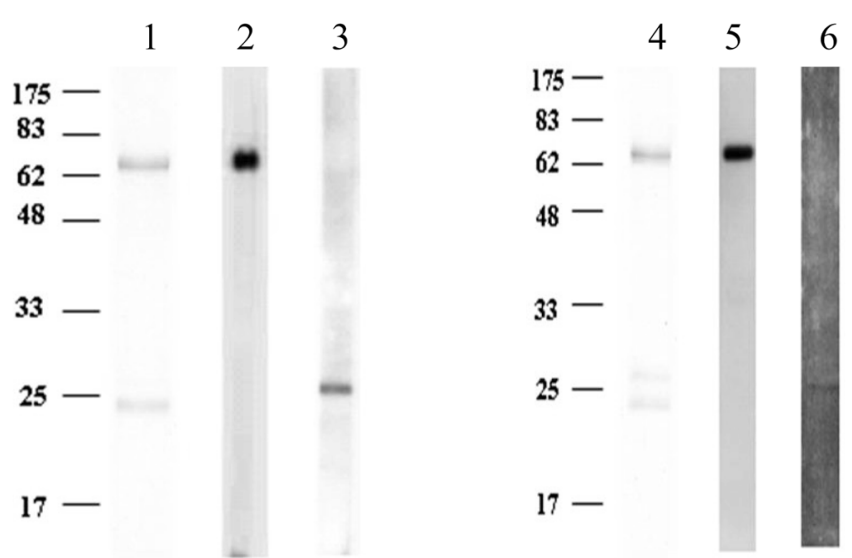

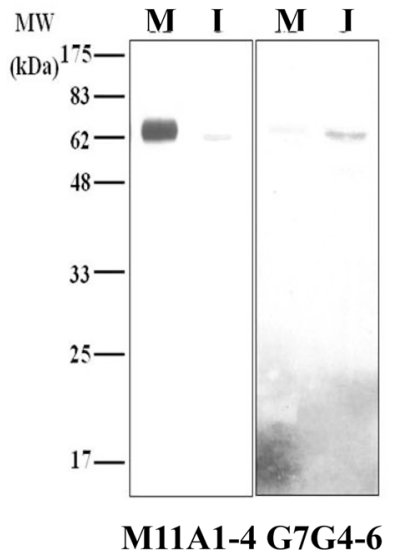

C

Fig. 3. Specificity and cross-reactivity of MAbs raised against olive flounder IMMlg and MBPIg. Panel A and B were immunoblot assays using specific MAbs to heavy and light chains of IMMlg and MBPIg, respectively. Lane 1, SDS-PAGE profiles of IMMIg; Lane 2, MAb (G7G4-6) to IMMIg heavy chain; Lane 3, MAb (G11B10-1) to IMMlg light chain; Lane 4, SDS-PAGE profiles of MBPIg; Lane 5, MAb (M11A1-4) to MBPIg heavy chain; Lane 6, MAb (M7C3-4) to MBPIg light chain. Panel C was immunoblot assays for cross-reactivity of IMMlg (I) and MBPIg (M) using MAbs (G7G4-6 and M11A1-4) for heavy chain of respective $\lg \mathrm{M}$.

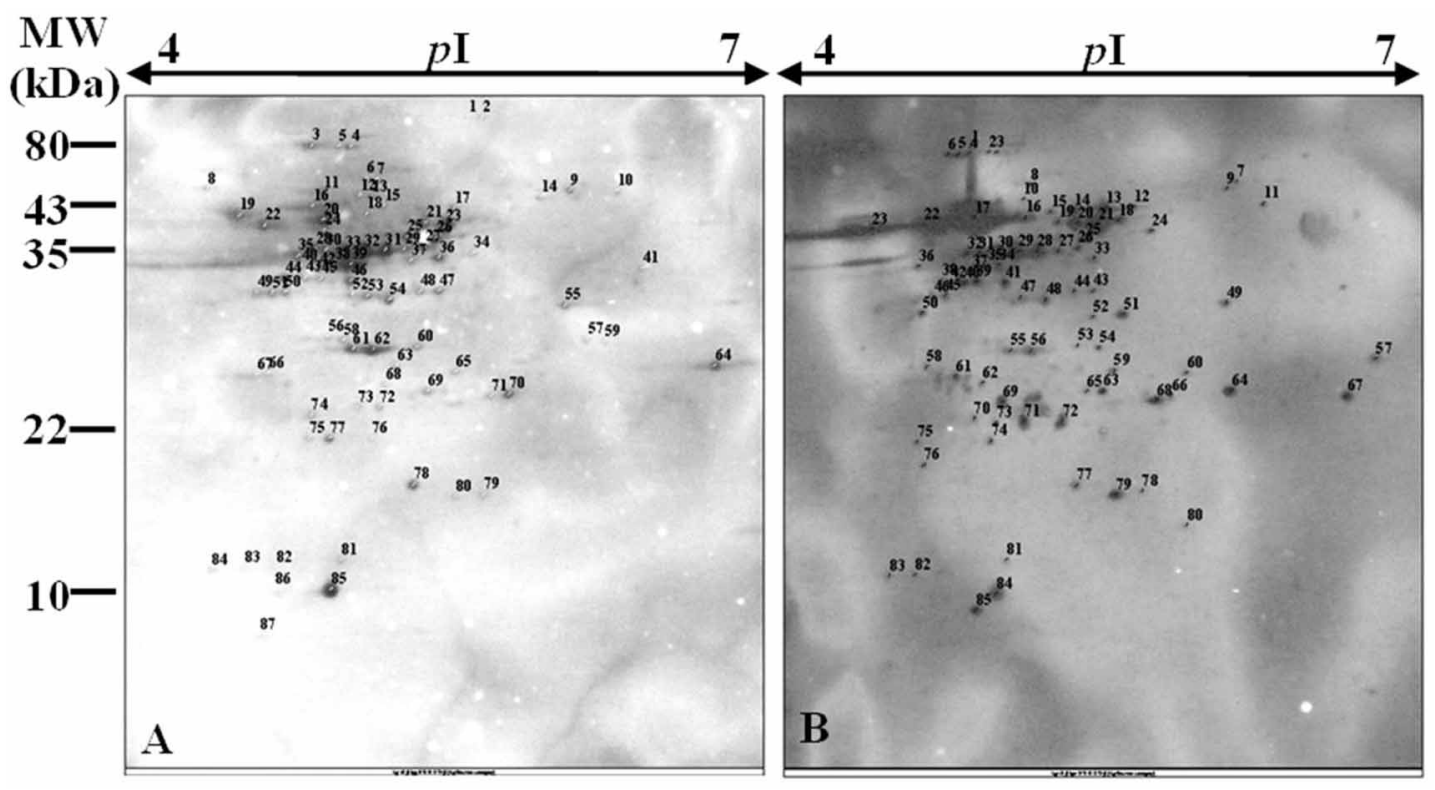

Fig. 4. 2-DE immunoblot profiles of L. garvieae KG9408 using specific MAbs to IMMlg (A) and MBPlg (B). Numbering of antigenic spots was performed by phoretix 2D software (Ver. 5.01; NonLinear Dynamics, UK)

garvieae KG9408 previously constructed in our laboratory (Shin et al. 2006b). An average of 85 and 87 antigenic spots $(n=3$ per $M A b)$ were observed in 2-DE immunoblot profiles of $L$. garvieae KG9408 detected with G7G4-6 and M11A1-4, respectively (Fig. 4). Most of the antigenic spots were distributed at $p \mathrm{p} \mathrm{4.5-5.7}$ and MW 20-60 kDa.

There were 56 common antigenic spots between both 2-DE immunoblot profiles. These antigenic spots included elongation factor Tu (EF-Tu), arginine deiminase (AD), ATP synthase alpha subunit (ATP synthase), dTDP-glucose 4,6-dehydratase (4,6-dehydratase), glyceraldehyde-3-phosphate dehydrogenase (GAPDH), phosphoglycerate kinase (PGK), DNA-directed RNA polymerase alpha chain (RNA polymerase), L-lactate dehydrogenase (LDH), UDP-galactose 4-epimerase (4-epimerase), 6-phosphofructokinase (PFK), fructose-bisphosphate aldolase (FBA), NADH-dependent enoyl-ACP reductase (ACP reductase), phosphoglycerate mutase (PGM), ornithine carbamoyltransferase 
Table 1. List of common antigenic spots reacted with IMMIg and MBPIg on 2-DE immunoblot profiles of $L$. garvieae KG9408

\begin{tabular}{ccccc|ccccc}
\hline IMMlg & MBPIg & Name of antigen & $p l$ & MW & IMMlg & MBPlg & Name of antigen & $p l$ & MW \\
\hline 3 & $4,5,6$ & $-*$ & 4.9 & 78.7 & 46 & 41 & LDH & 5.1 & 31.1 \\
4 & 3 & - & 5.1 & 78.3 & 47 & 43 & - & 5.5 & 30.4 \\
5 & 2 & - & 5.0 & 78.1 & 48 & 44 & - & 5.4 & 30.3 \\
7 & 8 & - & 5.2 & 60.7 & 50 & 45 & - & 4.8 & 30.3 \\
9 & 9 & IMPD & 6.1 & 57.1 & 51 & 46 & - & 4.7 & 30.2 \\
13 & 10 & - & 5.2 & 54.9 & 53 & 47 & 4 -epimerase & 5.1 & 30.0 \\
17 & 13 & - & 5.5 & 50.9 & 54 & 48 & - & 5.2 & 29.7 \\
18 & 16 & - & 5.1 & 49.1 & 55 & 49 & PFK & 6.0 & 29.3 \\
$16,20,24$ & 17 & EF-Tu & 4.9 & 47.0 & 60 & 53 & - & 5.4 & 26.1 \\
21 & 20 & AD & 5.4 & 46.2 & 61 & 55 & - & 5.1 & 26.0 \\
22 & 22 & ATP synthase & 4.7 & 45.2 & 62 & 56 & FBA & 5.2 & 26.0 \\
23 & 21 & AD & 5.5 & 45.1 & 64 & 57 & ACP reductase & 6.7 & 24.8 \\
26 & 25 & - & 5.5 & 41.2 & 65 & 59 & - & 5.5 & 24.4 \\
27 & 26 & $4,6-$ dehydratase & 5.4 & 37.9 & 66 & 58 & - & 4.7 & 24.3 \\
28 & 32 & PGK & 4.9 & 37.3 & 69 & 65 & PGM & 5.4 & 23.3 \\
29 & 27 & - & 5.3 & 37.3 & 70 & 66 & - & 5.8 & 23.1 \\
30 & 31 & - & 5.0 & 36.9 & 71 & 68 & - & 5.7 & 23.1 \\
31 & 28 & GAPDH & 5.2 & 36.9 & 73 & 69 & - & 5.1 & 22.4 \\
32 & 29 & GAPDH & 5.1 & 36.3 & 74 & 70 & - & 4.9 & 22.0 \\
33 & 30 & - & 5.0 & 36.0 & 77 & 74 & - & 5.0 & 20.6 \\
36 & 33 & - & 5.5 & 34.3 & 78 & 77 & - & 5.3 & 18.0 \\
38 & 35 & OCT & 5.0 & 32.4 & 79 & 78 & - & 5.7 & 17.4 \\
39 & 34 & - & 5.1 & 32.4 & 80 & 79 & - & 5.5 & 17.3 \\
42 & 37 & RNA polymerase & 4.9 & 32.0 & 81 & 81 & - & 5.0 & 14.6 \\
43 & 40 & - & 4.9 & 31.4 & 83 & 82 & - & 4.6 & 14.3 \\
44 & 38 & - & 4.8 & 31.3 & 84 & 83 & - & 4.4 & 14.3 \\
45 & 39 & - & 4.9 & 31.3 & 85 & 84 & - & 5.0 & 13.5 \\
\hline
\end{tabular}

*: non-identified protein; Identification of antigenic proteins was performed by comparing of 2-DE reference map of L. garvieae KG9408.

(OCT) and inosine-5'-monophosphate dehydrogenase (IMPD). In addition, we detected 31 IMMlg-specific spots including phosphomannomutase (PMM) and enolase and $29 \mathrm{MBPIg}$-specific spots including $30 \mathrm{~S}$ ribosomal protein S2 (ribosomal S2) and UDP-glucose pyrophospholylase (pyrophospholylase). These common and specific antigenic spots were summarized in Table 1 and 2, respectively.

\section{Discussion}

IgMs were successfully purified from olive flounder sera by affinity columns with goat lgG and MBP, but not protein A. Protein A is a cell wall component of Staphylococcus aureus that binds to a domain in the $\mathrm{Fc}$ region of Ig (Sasso et al., 1991; Harada et al., 1994). MBP is an animal lectin that acts in pathogen clearance and possesses a high specificity for the mannose regions of IgM (Koppel et al., 1994). These two molecules have been used for affinity column-based IgM purification from fish sera (Suzuki et al., 1990; Al-Harbi et al., 2000; Watts et al., 2001; Crosbie and Nowak, 2002; Bromage et al., 2004), as has goat IgG (Palenzuela et al., 1996; Watts et al., 2001). In the present work, we found that protein $A$ possessed a low affinity for olive flounder lgM versus the other capture ligands. This is consistent with other studies reporting that protein $\mathrm{A}$ had variable affinities for fish IgM; for example, protein A had low affinity for the IgM of rainbow trout and Atlantic salmon Salmo salar (Bromage et al., 2004), higher affinity for the IgM of striped bass Morone saxatilis, Mozambique tilapia Oreochromis mossambicus, Nile tilapia $O$. niloticus, barramundi Lates calcarifer (Bromage et al., 2004) and black rockfish Sebastes schlegeli (Kang et al., 2006) in affinity columns, and no affinity for the IgM of Atlantic halibut Hippoglossus hippoglossus in immunoblotting and dot blotting assays (Grove et al., 2006). These differences in affinity might be due to variations in the specificity of the protein A binding sites located in fish $\lg \mathrm{M}$.

SDS-PAGE analysis previously revealed that teleost IgM was comprised of a $70-81 \mathrm{kDa}$ heavy chain and a 22-32 kDa light chain. On the other hand, previous 2DE experiments showed that the spots corresponding to the heavy chain of human $\operatorname{lgM}$ were found within a $\mathrm{pl}$ range of 5.6 to 6.4 at a molecular weight (MW) of 80-82 kDa (Al-Harbi et al., 2000; Watts et al., 2001; Crosbie and Nowak, 2002; Bromage et al., 2004; Kang et al., 2006; Palenzuela et al., 1996; Kaattari and Piganelli, 1996). The $p l$ ranges and molecular weights of the heavy chain of IgM differed slightly in the emerald rockcod Ttrematomus bernacchii ( $p$ range 4.0-6.0, MW 
Table 2. List of specific antigenic spots reacted with IMMlg and MBPIg on 2-DE immunoblot profiles of L. garvieae KG9408

\begin{tabular}{|c|c|c|c|c|c|c|c|}
\hline \multicolumn{4}{|c|}{ Specific antigenic spots for IMMlg } & \multicolumn{4}{|c|}{ Specific antigenic spots for MBPIg } \\
\hline Spot No. & Name of antigen & $p l$ & MW & Spot No. & Name of antigen & $p l$ & MW \\
\hline 1 & - & 5.6 & 117.9 & 1 & - & 4.9 & 78.9 \\
\hline 2 & - & 5.7 & 116.1 & 4 & - & 4.9 & 75.8 \\
\hline 6 & - & 5.1 & 61.1 & 6 & - & 4.8 & 75.4 \\
\hline 8 & - & 4.4 & 57.6 & 7 & - & 6.1 & 62.0 \\
\hline 10 & - & 6.3 & 56.9 & 11 & - & 6.2 & 53.8 \\
\hline 11 & - & 4.9 & 56.3 & 12 & - & 5.7 & 52.6 \\
\hline 12 & - & 5.1 & 55.3 & 14 & - & 5.4 & 51.3 \\
\hline 14 & - & 5.9 & 54.8 & 15 & - & 5.3 & 50.5 \\
\hline 15 & - & 5.2 & 51.8 & 18 & - & 5.6 & 47.5 \\
\hline 16 & - & 4.9 & 51.7 & 19 & - & 5.3 & 46.9 \\
\hline 19 & enolase & 4.6 & 48.7 & 23 & - & 4.5 & 44.3 \\
\hline 24 & - & 4.9 & 43.7 & 24 & - & 5.7 & 43.9 \\
\hline 25 & - & 5.3 & 41.4 & 36 & - & 4.7 & 32.3 \\
\hline 34 & - & 5.6 & 36.0 & 42 & - & 4.9 & 31.0 \\
\hline 35 & PMM & 4.8 & 34.9 & 50 & - & 4.7 & 28.7 \\
\hline 37 & - & 5.3 & 33.3 & 51 & ribosomal S2 & 5.6 & 28.6 \\
\hline 40 & - & 4.8 & 32.3 & 52 & - & 5.5 & 28.4 \\
\hline 41 & - & 6.4 & 32.1 & 54 & - & 5.5 & 26.0 \\
\hline 49 & - & 4.6 & 30.3 & 60 & - & 5.9 & 24.4 \\
\hline 52 & - & 5.1 & 30.1 & 61 & - & 4.9 & 24.3 \\
\hline 56 & - & 5.0 & 26.9 & 62 & - & 5.0 & 23.9 \\
\hline 57 & - & 6.1 & 26.7 & 63 & - & 5.5 & 23.5 \\
\hline 58 & - & 5.0 & 26.6 & 64 & pyrophospholylase & 6.1 & 23.5 \\
\hline 59 & - & 6.2 & 26.6 & 67 & - & 6.6 & 23.3 \\
\hline 63 & - & 5.3 & 24.8 & 71 & - & 5.2 & 22.1 \\
\hline 67 & - & 4.6 & 24.3 & 72 & - & 5.3 & 22.1 \\
\hline 68 & - & 5.2 & 23.7 & 73 & - & 5.1 & 22.0 \\
\hline 72 & - & 5.2 & 22.4 & 75 & - & 4.7 & 21.1 \\
\hline 75 & - & 4.9 & 20.7 & 76 & - & 4.7 & 20.0 \\
\hline 76 & - & 5.2 & 20.7 & 80 & - & 5.9 & 17.2 \\
\hline 82 & - & 4.7 & 14.4 & 85 & - & 5.0 & 13.4 \\
\hline 86 & - & 4.7 & 13.5 & & & & \\
\hline 87 & - & 4.7 & 11.8 & & & & \\
\hline
\end{tabular}

*: non-identified protein; Identification of antigenic proteins was performed by comparing of 2DE reference map of $L$. garvieae KG9408.

$78 \mathrm{kDa}$ ) (Pucci et al., 2003), rainbow trout (pl 4.8-6.0, MW $76 \mathrm{kDa}$ ) and Arctic char Salvelinus alpinus (pl 5.06.5, MW $76 \mathrm{kDa}$ ) (Hordvik et al., 2002), whereas the light chain spots in all three fish species were broadly distributed across a pl range of 4 to 7 (Hordvik et al., 2002; Pucci et al., 2003). Consistent with these findings, the purified Igs from olive flounder showed bands of $68 \mathrm{kDa}$ and of 25-27 kDa in SDS-PAGE profile, and major spot groups at the ranges of pl 5.0-6.4 and MW 65-68 kDa, and pl 4-7 and MW 25-28 kDa on 2-DE profile. Based on the results of SDS-PAGE and 2-DE, bands and spots of approximately 66 and $68 \mathrm{kDa}$, and 25-27 $\mathrm{kDa}$ were believed to be the heavy chain and light chain, respectively. Furthermore, PMF followed by NCBI database searching identified the heavy chains of Ig proteins as IgM or IgM precursor.

Previously, 2-DE analysis was used to divide human IgM cryoglobulin (proteins precipitated from plasma or serum at low temperatures and resolubilized by warming) into 5 groups: $\mu$ chain of $\operatorname{lgM}$ ( $p$ l 5.6-6.4, $80 \mathrm{kDa}$ ), $\mu$ chain fragments of $\operatorname{IgM}, \operatorname{SP} \alpha$, J-chain and light chain (Tissot et al., 1994, 2002). On the other hand, degradation of IgM due to freezing shock was observed in hybrid bass (Morone saxatilis $\times M$. chrysops) by SDSPAGE analysis (Nitzan et al., 2003). Here, we found that MBPIg was consisted with 5 groups in 2-DE profiles. PMF analysis allowed us to identify groups (c), (a') and (d) as IgM or IgM precursor. Similarly, comparison of our 2-DE results to previously reported 2-DE maps of emerald rockcod, brown trout Salmo trutta and human IgMs (Hordvik et al., 2002; Pucci et al., 2003; Tissot et al., 1994, 2002) suggested that the spots found in group (b) and (b') represent the light chain of olive flounder IgM. In addition, the spots found in group (d) were thought to be $\mu$ chain fragments of IgM induced by freezing, as previously seen in IgM cryoglobulin from human and hybrid bass (Tissot et al., 1994, 2002; Nitzan et al., 2003). However, group (e) could not match with any groups on 2-DE profiles for IgM. On the other hand, computational image and PMF analysis showed 
that group (a') corresponded with group (a) on 2-DE profile of IMMIg. Therefore, MBP affinity column was thought to possess higher affinity to $\operatorname{lgM}$ consisted with heavy chain of $68 \mathrm{kDa}$. It might be difference in the degree of mannose glycosylation in the Fc regions of two different lgM types of olive flounder.

In a previous work, serum samples from olive flounder immunized with formalin-killed $E$. tarda were fractionated by gel filtration, which yielded two different proteins, high molecular protein (HMW) Ig and low molecular protein (LMW) Ig, both capable of agglutinating $E$. tarda. The heavy chain of the LMW Ig actually had a higher molecular weight than that of HMW Ig, as shown by SDS-PAGE analysis under reducing conditions (Bang et al., 1996). Similarly, LMW Igs were identified in fish such as the giant grouper Epinephelus itaira (Clem, 1971), rainbow trout (Elcombe et al., 1985), channel catfish Ictalurus punctatus (Lobb and Olson, 1988) and carp Cyprinus carpio (Rombout et al., 1993). In these fishes, the LMW Igs had different structures and antigenicities versus the tetramer $\operatorname{lgM}$, equivalent to the $\mathrm{HMW} \lg$ and various authors have suggested that the LMW Ig might be a distinct monomer formed as a degradative/cleavage product of tetramer IgM (Clem, 1971; Elcombe et al., 1985; Lobb and Olson, 1988; Rombout et al., 1993; Bang et al., 1996). On the other hand, two isotypes of IgM could be purified from serum of Atlantic salmon and brown trout with anion exchange chromatography followed by gel filtration. Furthermore, 2-DE analysis showed difference in $p l$ of heavy chains of respective IgM (Hordvik et al., 2002). In the present study, we noted that the heavy chain band from MBPIg was larger than that from IMMIg in SDS-PAGE analysis under reducing conditions and MAbs raised against IMMIg and MBPIg showed cross-reaction but different reactivity between both Igs. In light of the previous reports on LMW and HMW Igs in other fishes (Clem, 1971; Elcombe et al., 1985; Lobb and Olson, 1988; Rombout et al., 1993), it might be thought that MBPlg is likely to be LMW Ig different from a degradative/cleavage product, while IMMIg is likely to be HMW Ig, which exists as a tetramer in lgM.

The previous studies were reported to be differed with respect to function of both IgM types; for example, LMW and HMW IgM purified from rainbow trout antihaptin sera were distinguished form activating complement to lyse haptenated trout erythrocytes (Elcombe et al., 1985) and LMW Ig purified from olive flounder immunized with $E$. tarda exhibited lower antibody titers than the corresponding $\mathrm{HMW} \mathrm{Ig}$ in an agglutination test against E. tarda (Bang et al., 1996). For suggesting more concrete evidence than previous studies, proteomic tools were applied for analyzing function of both Igs by comparing $L$. garvieae antigens reacted with respective IgM types in the present study. Computational image analysis to 2-DE immunoblot profiles showed 56 common, 31 IMMlg-specific and 29 MBPIgspecific antigenic spots. Therefore, IMMlg and MBPIg were thought to play similar but different roles in recognition of L. garvieae antigens.

Kang et al. (2006) reported 22 antigenic spots of $L$. garvieae KG9408 recognized by black rockfish using 2$D E$ immunoblot assays. There were differences between 2-DE immunoblot profiles in previous and present study, in terms of antigenic profiles and the number of detected antigenic spots. These might be due to differences of protein loading volume for 2-DE immunoblot assays and humoral immune response between both fish species. On the other hand, novel finding of present study was 19 antigenic proteins identified from 22 antigenic spots on 2-DE immunoblot profile for L. garvieae. Functional analysis allowed us to divide these 19 antigens into 6 functional groups: translation, ribosomal structure and biogenesis (EF-Tu and $30 \mathrm{~S}$ ribosomal protein S2), transcription (DNA-directed RNA polymerase alpha chain), nucleotide transport and metabolism (IMPD), carbohydrate transport and energy production (PGK, GAPDH, LDH, PFK, FBA, enolase, phosphomannomutase, phosphoglycerate mutase and ATP synthase), amino acid transport and metabolism (AD and OCT), cell wall/membrane/envelope biogenesis (dTDP-glucose 4,6-dehydratase, UDP-galactose 4-epimerase and glucose-1-phosphate thymidylyltransferase) and lipid transport and metabolism (NADH-dependent enoyl-ACP reductase). Of these antigens, GAPDH has been reported as a vaccine candidate against Schistosoma mansonii and E. tarda (Argiro et al., 2000; Liu et al., 2005). In addition, PGK and OCT have been recognized as a protective antigen against various serotypes of Streptococcus agalactiae (Hughes et al. 2002). AD is a putative virulence factor observed on the capsular surface of $S$. suis and S. pyogenes (Winterhoff et al. 2002). These findings in association with two different antibody types might provide useful information in both studying antigens of $L$. garvieae and developing diagnostic marker and vaccine for this bacterium.

To sum up, we herein purified IMM- and MBP positive-IgM from olive flounder sera. The antigenic heterogeneity was noted between the lgMs, and proved that each IgM type was able to respond to specific antigens during immune response. These findings suggest that IMM- and MBP positive-lgM might play important roles during humoral immune response of olive flounder to $L$. garvieae infection.

\section{Acknowledgements}

This work was supported by a grant (R01-2001-00000242-0) from the Basic Research Program of the Korea Science \& Engineering Foundation. 


\section{References}

Al-Harbi, A. H., R. Truax and R. L. Thune (2000): Production and characterization of monoclonal antibodies against tilapia Oreochromis niloticus immunoglobulin. Aquaculture, 188, 219-27.

Argiro, L. L., S. S. Kohlstadt, S. S. Henri, H. H. Dessein, V. V. Matabiau, P. P. Paris, A. A. Bourgois and A. J. Dessein (2000): Identification of a candidate vaccine peptide on the $37 \mathrm{kDa}$ Schistosoma mansoni GAPDH. Vaccine, 18, 2039-2048.

Bang, J. D., J. W. Kim, S. D. Lee, S. I. Park, S. G. Chun, C. S. Jeong and J. W. Park (1996): Humoral immune response of flounder to Edwardsiella tarda: the presence of various sizes of immunoglobulins in flounder. Dis. Aquat. Org., 26, 197-203.

Bollag, D. M., M. D. Rozycki and S. J. Edelstein (1996): Affinity chromatography, In "Protein methods" (ed. by S. J. Edelstein). Wiley-Liss, Inc., New York, pp. 301-352.

Bromage, E. S., J. Ye, L. Owens, I. M. Kaattari and S. L. Kaattari (2004): Use of staphylococcal protein A in the analysis of teleost immunoglobulin structural diversity. Dev. Comp. Immunol., 28, 803-814.

Chang, P. H., C. W. Lin and Y. C. Lee (2002): Lactococcus garvieae infection of cultured rainbow trout, Oncorhynchus mykiss in Taiwan and associated biophysical characteristics and histopathology. Bull. Eur. Assoc. Fish Pathol., 22, 319-327.

Clem, L. W. (1971): Phylogeny of immunoglobulin structure and function. IV. Immunoglobulins of the giant grouper, Epinephelus itaira. J. Biol. Chem., 246, 9-15.

Crosbie, P. B. B. and B. F. Nowak (2002): Production of polyclonal antisera against barramundi (Lates calcarifer Bloch) serum immunoglobulin derived from affinity columns containing mannan-binding protein or staphylococcal protein A. Aquaculture, 211, 49-63.

Danilova, N., J. Bussmann, K. Jekosch, L. A. Steiner (2005): The immunoglobulin heavy-chain locus in zebrafish: identification and expression of a previously unknown isotype, immunoglobulin Z. Nat. Immunol., 6, 295-302.

Elcombe, B. M., R. J. Chang, C. J. Taves and J. L. Winkelhake (1985): Evolution of antibody structure and effector functions: comparative hemolytic activities of monomeric and tetrameric IgM from rainbow trout, Salmo gairdnerii. Comp. Biochem. Physiol. B., 80, 697-706.

Görg, A., C. Obermaier, G. Boguth, A. Harder, B. Scheibe, R. Wildgruber and W. Weiss (2000): The current state of twodimensional electrophoresis with immobilized $\mathrm{pH}$ gradients. Electrophoresis, 21, 1037-1053.

Grove, S., M. Tryland, C. M. Press and L. J. Reitan (2006): Serum immunoglobulin $\mathrm{M}$ in Atlantic halibut (Hippoglossus hippoglossus): characterisation of the molecule and its immunoreactivity. Fish Shellfish Immunol., 20, 97-112.

Hansen, J. D., E. D. Landis and R. B. Phillips (2005): Discovery of a unique $\lg$ heavy-chain isotype $(\lg T)$ in rainbow trout: implications for a distinctive B cell developmental pathway in teleost fish. Proc. Natl. Acad. Sci. USA., 102, 69196924.

Harada, M., S. Hayashimoto, H. Yomanaka, C. Terai, N. Kamatani and S. Kashiwazaki (1994): Molecular basis for the interaction between human $\operatorname{lgM}$ and staphylococcal protein A. Clin. Immunol. Immunopathol., 72, 394-401.

Hirono, I., B. H. Nam, J. Enomoto, K. Uchino and T. Aoki (2003): Cloning and characterisation of a cDNA encoding Japanese flounder Paralichthys olivaceus IgD. Fish Shellfish Immunol., 15, 63-70.

Hordvik, I., F. Berven, S. Solem, F. Hatten and C. Endresen
(2002): Analysis of two IgM isotypes in Atlantic salmon and brown trout. Mol. Immunol., 39, 313-321.

Hughes, M. J., J. C. Moore, J. D. Lane, R. Wilson, P. K. Pribul, Z. N. Younes, R. J. Dobson, P. Everest, A. J. Reason, J. M. Redfern, F. M. Greer, T. Paxton, M. Panico, H. R. Morris, R. G. Feldman and J. D. Santangelo (2002): Identification of major outer surface proteins of Streptococcus agalactiae. Infect. Immun., 70, 1254-1259.

Kaattari S. L. and D. Piganelli (1996): The specific immune system: humoral defence, In "The fish immune system: organism, pathogen, and environment" (ed. by G. Iwama and T. Nakanishi). Academic Press, San Diego, pp. 207-254.

Kang, S. H., G. W. Shin, K. J. Palaksha, Y. S. Shin, Y. R. Kim, E. Y. Lee, E. H. Suh, N. E. Huh, M. J. Oh, and T. S. Jung (2006): Efficacy of protein A-HRP in an immunological study of black rockfish (Sebastes schlegeli Higendorf) humoral immune responses. Fish Shellfish Immunol., 20, 295-304.

Koppel, R., M. Litvak and B. Solomon (1994): Affinity purification of a mannose-binding protein, a sensitive tool in the diagnostics of IgM, via site-directed phosphorylated mannan bound to alumina. J. Chromatogr. B Biomed. Appl., 662, 191-196.

Kusuda. R., K. Kawai, T. Toyoshima and I. Komatsu (1976): A new pathogenic bacterium belonging to the genus Streptococcus, isolated from epizootic of cultured yellowtail. Nippon Suisan Gakkai Shi., 42, 1345-1352.

Lee, U. H., H. J. Pack, J. W. Do, J. D. Bang, H. R. Cho, B. K. Ko, C. W. Nam, D. H. Choi, H. K. Yu, C. S. Jeong, E. S. Han and J. W. Park (2001): Flounder (Paralichthys olivaceus) cDNA encoding a secreted immunoglobulin M heavy chain. Fish Shellfish Immunol., 11, 537-540.

Liu, Y., S. Oshima, K. Kurohara, K. Ohnishi and K. Kawai (2005): Vaccine efficacy of recombinant GAPDH of Edwardsiella tarda against edwardsiellosis. Microbiol. Immunol. 49, 605-612.

Lobb, C. J. and M. O. Olson (1988): Immunoglobulin heavy H chain isotypes in a teleost fish. J. immunol., 141, 12361245.

Mini, R., G. Bernardini, A. M. Salzano, G. Renzone, A. Scaloni, N. Figura and A. Santucci (2006): Comparative proteomics and immunoproteomics of Helicobacter pylori related to different gastric pathologies. J. Chromatogr. B Analyt. Technol. Biomed. Life Sci., 833, 63-79.

Nitzan S, B. Shwartsburd and E. D. Heller (2003): The effect of storing hybrid bass (Morone saxatilis $\times$ M. chrysops) sera at freezing temperatures on antibody titers. Fish Shellfish Immunol., 5, 341-347.

Ooyama, T., Y. Hirokawa, T. Minami, H. Yasuda, T. Nakai, M. Endo, L. Ruangpan and T. Yoshida (2002): Cell-surface properties of Lactococcus garvieae strains and their immunogenicity in the yellowtail Seriola quinqueradiata. Dis. Aquat. Org., 51, 169-177.

Palenzuela, O., A. Sitja-Bobadilla and P. Alvarez-Pellitero (1996): Isolation and partial characterization of serum immunoglobulins from sea bass (Dicentrarchus labrax L.) and gilthead sea bream (Sparus aurata L.). Fish Shellfish Immunol., 6, 81-94.

Pucci, B., M. R. Coscia and U. Oreste (2003): Characterization of serum immunoglobulin $\mathrm{M}$ of the Antarctic teleost Trematomus bernacchii. Comp. Biochem. Physiol. B Biochem. Mol. Biol., 135, 349-357.

Rombout, J. H., N. Taverne, M. van de Kamp and A. J. Taverne-Thiele (1993): Differences in mucus and serum immunoglobulin of carp (Cyprinus carpio L.). Dev. Comp. Immunol., 17, 309-317.

Roberts, R. J. (2001): The bacteriology of teleost, In "Fish pa- 
thology" (ed. by R. J. Roberts). W. B. Saunders, London, pp. 324-325.

Sasso, E. H., G. J. Siverman and M. Mannik (1991): Human IgA and $\lg G \mathrm{~F}\left(\mathrm{ab}^{\prime}\right)_{2}$ that bind to staphylococcal protein $A$ belong to the $\mathrm{V}_{\mathrm{H}}$ III subgroup. J. Immunol., 147, 18771883.

Shin, G. W., K. J. Palaksha, H. H. Yang, Y. S. Shin, Y. R. Kim, E. Y. Lee. H. Y. Kim, Y. J. Kim, M. J. Oh, T. Yoshida and T. S. Jung (2006a): Discrimination of streptococcosis agents in olive flounder (Paralichthys olivaceus). Bull. Eur. Assoc. Fish Pathol., 26, 68-79.

Shin, G. W., K. J. Palaksha, H. H. Yang, Y. S. Shin, Y. R. Kim YR, E. G. Lee EU, M. J. Oh and T. S. Jung (2006b): Partial two-dimensional gel electrophoresis (2-DE) maps of Streptococcus iniae ATCC29178 and Lactococcus garvieae KG9408. Dis. Aquat. Org., 70, 71-79.

Smith, S. A. (1992): Affinity purification of serum immunoglobulin from fish, In "Techniques in fish immunology: fish Immunology technical communications no. 2." (ed. by J. S. Stolen, T. C. Flectcher, D. P. Anderson, S. L. Kaattari and A. F. Rowley). SOS Publication, New Jersey, pp. 125-130.

Suzuki, Y., M. Tanaka, K. Aida and I. Hanyu (1990): Affinity of fish immunoglobulin to protein A. Nippon Suisan Gakkai Shi., 56, 831.

Tissot, J. D., J. A. Schifferli, D. F. Hochstrasser, C. Pasquali, F. Spertini, F. Clement, S. Frutiger, N. Paquet, G. J. Hughes and P. Schneider (1994): Two-dimensional polyacrylamide gel electrophoresis analysis of cryoglobulins and identification of an IgM-associated peptide. J. Immunol. Methods, $12,63-75$.

Tissot, J. D., J. C. Sanchez, F. Vuadens, A. Scherl, J. A. Schifferli, D. F. Hochstrasser, P. Schneider and M. A. Duchosal (2002): IgM are associated to Sp alpha (CD5 antigen-like). Electrophoresis, 23, 1203-1206.

Tizard I. R. (2000): Anitibodies: soluble forms of BCR, In "Veterinary immunology an introduction." (ed. by I. R. Tizard). Saunders, Philadelphia, pp. 139-148.

Twine, S. M., M. D. Petit, H. Shen, N. C. Mykytczuk, J. F. Kelly and J. W. Conlan (2006): Immunoproteomic analysis of the murine antibody response to successful and failed immunization with live anti-Francisella vaccines. Biochem. Biophys. Res. Commun., 346, 999-1008.

Watts, M., B. L. Munday and C. M. Burke (2001): Isolation and partial characterisation of immunoglobulin from southern bluefin tuna Thunnus maccoyii Castelnau. Fish Shellfish Immunol., 11, 491-503.

Winterhoff, N., R. Goethe, P. Gruening, M. Rohde, H. Kalisz, H. E. Smith and P. Valentin-Weigand (2002): Identification and characterization of two temperature-induced surfaceassociated proteins of Streptococcus suis with high homologies to members of the arginine deiminase system of Streptococcus pyogenes. J. Bacteriol., 184, 67686776. 